\title{
Óleos essenciais e vegetais no controle in vitro de Colletotrichum gloeosporioides
}

RAMOS, K. ${ }^{\text {; }}$ ANDREANI JUNIOR, R.1; KOZUSNY- ANDREANI, D.I. ${ }^{*}$

1 Universidade Camilo Castelo Branco, Departamento de Pós Graduação Strictu Sensu em Ciências Ambientais, Estrada Projetada F-1, s/n. Fazenda Santa Rita - Fernandópolis-SP CEP: 15600-000. *Autor para correspondência: doraines@terra.com.br

\begin{abstract}
RESUMO: O objetivo deste trabalho foi avaliar a atividade antifúngica de óleos essenciais e vegetais no controle in vitro de Colletotrichum gloeosporioides, agente causal da antracnose em pós-colheita de frutíferas. Treze óleos essenciais foram utilizados em concentrações de 0,00\%, $0,40 \%, 0,80 \%, 1,70 \%, 3,20 \%, 6,25 \%, 12,50 \%, 25,00 \%, 50,00 \%$ e 100,00\%, e uma linhagem padrão de Colletotrichum gloeosporioides. Foram avaliadas a concentração inibitória mínima e a concentração mínima fungicida a fim de caracterizar o potencial de cada um dos óleos essenciais avaliados. Verificou-se que os óleos utilizados apresentaram atividade fungicida em diferentes concentrações, as quais variaram de 0,80\% (melaleuca), 3,20\%, (eucalipto), 6,25\% (limão, capim limão, cravo da índia, canela e nim), 12,5\% (hortelã e citronela), 25\% (copaíba), $50 \%$ (coco e gengibre) e 100\% (manjericão). O óleo de nim apresentou maior redução da carga microbiana em função do tempo de exposição, sendo necessários 30 minutos para anulação da contagem microbiana. O efeito antifúngico dos óleos essenciais, para controle de Colletotrichum gloeosporioides, depende da planta e da concentração empregada.
\end{abstract}

Palavras-chave: antracnose, frutíferas, antifúngicos, plantas medicinais.

\begin{abstract}
Essential and vegetal oils in the in vitro control of Colletotrichum gloeosporioides. This study aimed to evaluate the antifungal effect of essential and vegetal oils in the in vitro control of Colletotrichum gloeosporioides, a causal agent of anthracnose in fruit postharvest. Thirteen essential oils were used at concentrations of $0.00 \%, 0.40 \%, 0.80 \%$, $1.70 \%, 3.20 \%, 6.25 \%, 12.50 \%, 25.00 \%, 50.00 \%$, and $100.00 \%$, and also a standard strain of Colletotrichum gloeosporioides, The minimum inhibitory concentration and minimum fungicidal concentration were assessed to characterize the potential of each of the essential oils tested. We found that used oils showed fungicidal activity at different concentrations, which varied in $0.80 \%$ (Melaleuca alternifólia), 3.20\%, (Eucalyptus globulus), 6.25\% (Citrus limonium, Cymbopogon citratus, Syzygium aromaticum, Cinnamomum zeylanicum, and Azadirachta indica), 12.5\% (Mentha piperita and Cymbopogon winterianus), 25\% (Copaifera langsdorfii), 50\% (Cocos nucifera and Zingiber officinale), and 100\% (Ocimum basilicum). The Azadirachta indica oil showed greater reduction of microbial load because of the exposure time, and took 30 minutes for annulment of microbial count. The antifungal effect of essential oils to control Colletotrichum gloeosporioides depends on the plant and quantity of concentration.
\end{abstract}

Keywords: anthracnose, fruit plants, antifungal, medicinal plants.

\section{INTRODUÇÃO}

A principal preocupação dos agricultores na produção de frutas está relacionada com a manifestação de doenças na fase de pós-colheita, entre elas, a antracnose, que é causada pelo fungo Colletotrichum gloeosporioides Penz. (Silva et al., 2009).

A antracnose é a doença de pós-colheita de maior ocorrência nas regiões tropicais e subtropicais do mundo, podendo atingir frutas como o mamão (Carica papaya L.), a manga (Mangifera indica L.), a banana (Musa spp.), o caju (Anacardium occidentale L.), o maracujá (Passiflora edulis Sims) (Lima Filho et al., 2003) e a goiaba (Psidium guajava L.), entre outras (Silva et al., 2006). As perdas de pós-colheita em frutos, antes de chegarem à mesa do consumidor, em muitos casos são superiores a $50 \%$, e os que chegam, nem sempre apresentam a qualidade

Recebido para publicação em 06/10/2015

Aceito para publicação em 22/08/2016

10.1590/1983-084X/15_192

Rev. Bras. PI. Med., Campinas, v.18, n.2, supl. I, p.605-612, 2016. 
desejada (Tavares, 2004).

O controle químico com fungicidas aplicado como medida isolada, não atua de forma satisfatória na redução das perdas provocadas pela antracnose (Peruch et al., 2009), além do fato de que o uso contínuo e intensivo de fungicidas interrompe o controle biológico natural, uma vez que organismos não alvo podem ser afetados, ocasionando ainda, problemas ambientais (Soylu et al., 2010), e o surgimento de patógenos resistentes, ocasionando surtos de doenças (Lee et al., 2008). Estes problemas a saúde humana e ao meio ambiente causados pelo uso indiscriminado de agrotóxicos tem levado a uma busca por produtos e tecnologias alternativas de controle que seja capaz de reduzir o uso desses compostos químicos na produção de alimentos (Silva et al., 2010).

Entre os meios alternativos que podem ser adotados por produtores de frutíferas, a busca de plantas dotadas de compostos capazes de substituir os atuais produtos químicos é uma alternativa bastante promissora de grande importância econômica e ecológica. A natureza pode apresentar uma variedade de plantas que podem ser resistentes a diversos patógenos, incluindo substâncias com características fungicidas (Venturoso et al., 2010). Estudos realizados com óleos essenciais e extratos aquosos obtidos de espécies vegetais apresentamse eficazes, no controle de doenças pós-colheita como a antracnose em frutíferas, devido à ação fungitóxica. Dentre estas espécies se encontram o eucalipto (Eucalyptus citriodora Hooker M.) (Venturoso et al., 2010), a andiroba (Carapa guianensis Aubl.), o coco (Cocos nucifera L.), as sementes de uva (Vitis vinifera L.), a amêndoa (Prunus amygdalus Batsch), o hortelã (Mentha sp.) (Sousa et al., 2012), o capim-limão (Cymbopogon citratus (D.C.) Stapf.), a menta (Mentha piperita L.) (Carnelossi et al., 2009; Sarmento-Brum et al., 2014; Bhuyan, et al., 2015), e o cravo da índia (Syzygium aromaticum (L.) Merr. \& L. M. Perry) (Silva et al., 2014).

Sendo a antracnose uma das doenças fúngicas de pós-colheita mais importantes, os extratos de plantas e os óleos essencias e vegetais podem ser considerados fungicidas potenciais para o seu controle. A inibição do crescimento dos fungos fitopatogênicos, por estes antimicrobianos naturais é devido às substâncias bioativas encontradas em plantas (Chiejina \& Ukeh, 2012, Silva et al., 2014). Neste contexto, o presente trabalho teve como objetivo avaliar o efeito inibitório de óleos essenciais e vegetais no controle in vitro de Colletotrichum gloeosporioides. Para tal finalidade foram determinandas as concentrações inibitórias mínimas (CIM), as concentrações fungicidas mínimas (CFM) e a sobrevivência do fungo na presença dos óleos em função do tempo.

\section{MATERIAL E MÉTODO}

O experimento foi desenvolvido no Laboratório de Microbiologia, da Universidade Camilo Castelo Branco (UNICASTELO), localizado na cidade de Fernandópolis, localizada no Noroeste de São Paulo, no período de janeiro a julho de 2014.

Os tratamentos constaram do uso de dez óleos essências sendo eles, o nim (Azadirachta indica A. Juss-Família Meliaceae), o cravo da índia (Syzygium aromaticum (L.) Merr. \& L. M. PerryFamília Myrtaceae), a hortelã pimenta (Mentha piperita L.-Família Lamiaceae), a melaleuca (Melaleuca alternifolia Cheel-Família Myrtaceae), o limão (Citrus limonium L.-Família Rutaceae), - copaíba (Copaifera langsdorfii Desf.-Familia Fabaceae), o eucalipto (Eucalyptus globulus Labill.Família Myrtaceae), o gengibre (Zingiber officinale Roscoe-Família Zingiberaceae), o manjericão (Ocimum basilicum L.-Família Lamiaceae), o capim limão (Cymbopogon citratus (DC) Stapf.Família Poaceae), a canela (Cinnamomum zeylanicum Breyn.-Família Lauraceae), a citronela (Cymbopogon winterianus JowittFamília Poaceae), e de três óleos vegetais: o nim (Azadirachta indica A. Juss-Família Meliaceae), o copaíba (Copaifera langsdorfii Desf.- Familia Fabaceae), e o coco (Cocos nucifera L.-Familia Arecaceae), em concentrações que variaram de 0,00 a $100,00 \%$, sendo elas: $0,40 \%, 0,80 \%, 1,70 \%$, $3,20 \%, 6,25 \%, 12,50 \%, 25,00 \%, 50,00 \% 100,00 \%$ e o controle negativo (Ogbebor et al., 2007). A atividade antifúngica foi avaliada pelo método de microdiluição em placa de 96 poços, seguindo os protocolos do Clinical Laboratory Standard Institute (CLSI, 2008).

Os óleos essenciais e os óleos vegetais foram adquiridos em comércios especializados. Todos os óleos essenciais e os vegetais de coco e de copaíba foram da BioEssência ${ }^{\circledR}$ (Anvisa MS 2.048.81.6); e óleo nim marca Base $\mathrm{Nim}^{\circledast}$ (Anvisa 3.4191.0002.001-4).

Foi utilizada uma linhagem padrão de Colletotrichum gloeosporioides, (Glomerella cingulata, (Stoneman.) Spauld. \& v. Schrenk, CCT 5177, adquirida na Fundação André Tosello, Campinas-SP). Para o preparo do inóculo, culturas de sete dias em meio ágar batata dextrose (BDA, Himedia ${ }^{\circledR}$ foram transferidas para meio triptecaseina broth (Oxoid ${ }^{\varpi}$ ) e incubadas a $37^{\circ} \mathrm{C}$ por sete dias, quando se procedeu a 
centrifugação (4000 rpm) por cinco minutos. Em seguida o sobrenadante foi desprezado e o material precipitado ressuspendido em solução estéril de $\mathrm{NaCl}(0,5 \%)$ e novamente submetido a centrifugação. Este procedimento foi repetido cinco vezes com a finalidade de retirar os componentes do meio de cultura.

A concentração inibitória mínima (CIM) dos óleos essenciais foi determinada seguindo os protocolos do CLSI (2008), utilizando-se o método de microdiluição em placas. Após incubação a $37^{\circ} \mathrm{C}$ por cinco dias a CIM foi avaliada, sendo que a presença de células fúngicas viáveis nas concentrações não inibitórias foi determinada pela adição, em cada amostra, do corante 2,3,5 -Triphenyltetrazolium Chloride, no volume de 50 $\mu \mathrm{L}$. Isto tornou possível distinguir as amostras vivas, coloridas de vermelho, daquelas mortas que mantiveram a sua cor. A concentração inibitória mínima foi considerada como a menor concentração de óleo essencial capaz de inibir o desenvolvimento fúngico (Sylvester, 2011).

A concentração fungicida mínima (CFM) foi determinada após a obtenção dos resultados da concentração inibitória mínima. As placas de microdiluição contendo poços com crescimentos visíveis ou não, foram agitados vigorosamente com o auxilio do micropipetador, e em seguida $100 \mu \mathrm{L}$ da solução de cada poço foram transferidos para placas de Petri contendo meio agar batata dextrose e incubados a $37^{\circ} \mathrm{C}$ por sete dias, sendo que a avalição foi periódica. Designou-se como concentração fungicida mínima a concentração mínima em que não ocorreu crescimento fúngico (Favre et al., 2003).

Uma vez determinada a concentração inibitória mínima e a concentração fungicida mínima, as mesmas foram utilizadas para avaliar o crescimento fúngico na presença dos óleos em função do tempo, determinando-se curva de sobrevivência de acordo com a metodologia descrita por Sforcin et al. (2000). Os ensaios foram desenvolvidos em quadruplicata.

Para a avaliação do tempo necessário para reduzir a carga microbiana para valores nulos, as contagens microbianas, realizadas a cada dez minutos, foram analisadas de acordo com suas respectivas variações percentuais em cada período avaliado. O período referente à análise da contagem microbiana foi de 0 a 100 minutos. A variação percentual da contagem microbiana consistiu da seguinte relação:
Essa relação foi empregada para todos os tempos avaliados, até o tempo máximo de 100 minutos. De acordo com a expressão acima, variações negativas resultam em diminuição na contagem microbiana e variações positivas em aumento da contagem microbiana ao longo do tempo avaliado.

A avaliação da contagem microbiana ao longo do tempo de exposição do fungo ao óleo essencial foi avaliada pela abordagem da variação da contagem microbiana percentual, a fim de observar as variações da contagem microbiana ao longo do tempo estudado.

Os dados foram avaliados por meio do teste não paramétrico de Kruskal-Wallis com teste de comparação múltipla de Dunn post-hoc quando $p<0,05$. O nível de significância adotado para os testes estatísticos foi de 0,05.

\section{RESULTADO E DISCUSSÃO}

O fungo Colletotrichum gloeosporioides apresentou-se sensível aos óleos essenciais e vegetais utilizados no presente estudo, onde foi possível determinar as concentrações fungicidas mínimas para cada um deles. Os óleos utilizados apresentaram atividade fungicida em diferentes concentrações, as quais variaram de $0,80 \%$ (melaleuca), 3,20\%, (eucalipto), 6,25\% (limão, capim limão, cravo da índia, canela e nim), 12,5\% (hortelã e citronela), 25\% (copaíba), 50\% (coco e gengibre) e $100 \%$ (manjericão) (Tabela 1).

De acordo com os resultados da Tabela 2 observa-se que houve diferenças significativas entre as médias das variações percentuais da contagem microbiana $(p<0,001)$ proporcionada pelos óleos essenciais e vegetais. O teste de comparação múltipla forneceu dados que pressupõem maior eficácia dos óleos de melaleuca $(-99,2 \%)$, copaíba $(-99,4 \%)$, capim limão $(-98,7 \%)$ e nim $(-99,9 \%)$, sendo que os mesmos apresentaram maiores reduções da contagem microbiana (Tabela 2). Os compostos bioativos desses óleos foram mais eficazes, sendo que para melaleuca, copaíba e capim limão foram necessários 40 minutos de exposição para eliminar a carga microbiana, enquanto que para o óleo de nim foram necessários somente 30 minutos de exposição para obter o mesmo efeito (Figura 1).

$$
\text { Contagem microbiana } 0-10 \mathrm{mim}(\%)=\frac{(\text { Contagem 10mim }- \text { Contagem 0min })}{\text { Contagem 10min }} .100
$$


TABELA 1. Efeito inibitório de diferentes concentrações de óleos essenciais e vegetais sobre Colletotrichum gloeosporioides.

\begin{tabular}{lcccccccccccc}
\hline Óleos & $\begin{array}{l}\text { Controle } \\
\text { negativo }\end{array}$ & $0,4 \%$ & $0,8 \%$ & $1,7 \%$ & $3,2 \%$ & $6,25 \%$ & $12,5 \%$ & $25 \%$ & $50 \%$ & $100 \%$ & CIM & CFM \\
\hline Hortelã & $1,0.10^{\circ}$ & $1,0.10^{4}$ & $1,3.10^{2}$ & $1,2.10^{2}$ & $9,6.10^{1}$ & $2,7.10^{1}$ & 0 & 0 & 0 & 0 & $6,25 \%$ & $12,5 \%$ \\
Melaleuca & $1,0.10^{6}$ & $7,3.10^{3}$ & 0 & 0 & 0 & 0 & 0 & 0 & 0 & 0 & $0,8 \%$ & $0,8 \%$ \\
Limão & $1,0.10^{6}$ & $5,4.10^{3}$ & $3,2.10^{2}$ & $9,2.10^{1}$ & $5,0.10^{1}$ & 0 & 0 & 0 & 0 & 0 & $3,2 \%$ & $6,25 \%$ \\
Copaíba & $1,0.10^{6}$ & $6,3.10^{4}$ & $1,1.10^{4}$ & $2,1.10^{3}$ & $8,3.10^{2}$ & $5,0.10^{1}$ & $1,7.10^{1}$ & 0 & 0 & 0 & $25 \%$ & $25 \%$ \\
Eucalipto & $1,0.10^{6}$ & $9,0.10^{3}$ & $1,8.10^{3}$ & $4,6.10^{1}$ & 0 & 0 & 0 & 0 & 0 & 0 & $1,7 \%$ & $3,2 \%$ \\
Gengibre & $1,0.10^{6}$ & $3,5.10^{5}$ & $5,7.10^{4}$ & $7,6.10^{3}$ & $1,8.10^{3}$ & $9,0.10^{2}$ & $1,4.10^{2}$ & $5,0.10^{1}$ & 0 & 0 & $50 \%$ & $50 \%$ \\
Manjericão & $1,0.10^{6}$ & $8,3.10^{5}$ & $2,3.10^{4}$ & $5,6.10^{4}$ & $9,4.10^{3}$ & $1,2.10^{3}$ & $9,5.10^{2}$ & $1,2.10^{2}$ & $4,3.10^{1}$ & 0 & $100 \%$ & $100 \%$ \\
Coco & $1,0.10_{6}$ & $5,0.10^{4}$ & $1,8.10^{4}$ & $1,6.10^{4}$ & $1,2.10^{3}$ & $8,1.10^{2}$ & $5,0.10^{1}$ & $4,0.10^{1}$ & 0 & 0 & $25 \%$ & $50 \%$ \\
Capim limão & $1,0.10^{6}$ & $8,8.10^{4}$ & $1,8.10^{3}$ & $6,1.10^{2}$ & $8,7.10^{1}$ & 0 & 0 & 0 & 0 & 0 & $3,2 \%$ & $6,25 \%$ \\
Cravo & $1,1.10^{6}$ & $2,3.10^{5}$ & $1,7.10^{4}$ & $2,0.10^{2}$ & $8,7.10^{1}$ & 0 & 0 & 0 & 0 & 0 & $6,25 \%$ & $6,25 \%$ \\
Canela & $1,0.10^{6}$ & $1,6.10^{4}$ & $1,5.10^{3}$ & $1,9.10^{2}$ & $6,7.10^{1}$ & 0 & 0 & 0 & 0 & 0 & $3,2 \%$ & $6,25 \%$ \\
Citronela & $1,0.10^{6}$ & $3,6.10^{4}$ & $3,2.10^{3}$ & $8,8.10^{2}$ & $2,6.10^{1}$ & $4,0.10^{1}$ & 0 & 0 & 0 & 0 & $6,25 \%$ & $12,5 \%$ \\
Nim & $1,1.10^{6}$ & $4,3.10^{4}$ & $1,4.10^{4}$ & $1,1.10^{3}$ & $2,9.10^{1}$ & 0 & 0 & 0 & 0 & 0 & $3,2 \%$ & $6,25 \%$ \\
\hline
\end{tabular}

Valores médios da contagem microbiana. CIM: concentração inibitória mínima. CFM: Concentração fungicida mínima

TABELA 2. Variação percentual da contagem microbiana em relação aos óleos essenciais e vegetais avaliados.

\begin{tabular}{|c|c|c|c|c|}
\hline Óleos & $\mathrm{N}^{*}$ & Média $\pm \mathrm{DP}$ & Mediana $(\mathrm{Md})^{2}$ & Valor $\mathrm{p}^{1}$ \\
\hline Hortelã & 27 & $-60,4 \pm 50,4$ & $-71,2^{b}$ & \\
\hline Melaleuca & 12 & $-98,3 \pm 2,1$ & $-99,2^{a}$ & \\
\hline Limão & 21 & $-89,3 \pm 6,0$ & $-88,4 a b$ & \\
\hline Copaíba & 12 & $-95,7 \pm 7,1$ & $-99,4^{a}$ & \\
\hline Eucalipto & 21 & $-87,5 \pm 12,2$ & $-92,0 \mathrm{ab}$ & \\
\hline Gengibre & 21 & $-82,7 \pm 22,9$ & $-90,0^{a b}$ & \\
\hline Manjericão & 15 & $-84,0 \pm 30,9$ & $-97,0^{a b}$ & $<0,001$ \\
\hline Coco & 18 & $-87,4 \pm 15,7$ & $-94,5^{a b}$ & \\
\hline Capim limão & 12 & $-98,5 \pm 1,2$ & $-98,7^{a}$ & \\
\hline Cravo da índia & 30 & $-47,0 \pm 72,4$ & $-77,8^{b}$ & \\
\hline Canela & 18 & $-91,0 \pm 6,4$ & $-92,0 \mathrm{ab}$ & \\
\hline Citronela & 9 & $-96,0 \pm 5,8$ & $-99,8^{a b}$ & \\
\hline $\mathrm{Nim}$ & 9 & $-99,3 \pm 0,9$ & $-99,9^{a}$ & \\
\hline
\end{tabular}

Martinez, (2002), constatou que óleo de sementes de nim tem uma maior eficiência devido à presença da azadiractina nas sementes em relação ao extrato de folhas. Silva et al. (2011), constataram que a utilização do óleo de nim, na concentração de $200 \mu \mathrm{g} / \mathrm{mL}$ de ingrediente ativo azadiractina, inibia o crescimento micelial em $60 \%$ e em $53,8 \%$ da germinação de conídios do patógeno Colletotrichum gloeosporioides isolado de folhas de seringueira. Solino et al. (2012), constataram que os óleos de nim, soja, copaíba e de jatobá apresentaram atividade fungicida in vitro sobre a antracnose, sendo que os óleos de soja e de nim reduziram em maior grau a gravidade da doença.
Entretanto, assim como no presente estudo, outros autores também verificaram que o óleo de copaíba (Copaifera langsdorfii Desf.) é eficiente no controle de alguns fungos. A atividade antifúngica do óleo de copaíba está relacionada à presença de substâncias químicas biologicamente ativas, entre elas os diterpenos como o ácido copálico e os sesquiterpenos como o beta-bisaboleno e o betacariofileno (Pieri et al., 2009). Oliveira et al. (2006), relataram que de uma maneira geral as espécies do gênero Copaifera, podem ser utilizadas no controle de espécies fúngicas in vitro. Estudos realizados por Solino et al. (2012) constataram que com apenas $0,25 \mathrm{~mL} . \mathrm{L}^{-1}$, o óleo resina de copaíba apresenta redução da antracnose in vivo no maracujazeiro amarelo, e que aumenta em quatro dias a mais a vida útil dos frutos, chegando em até doze dias quando tratados pelo óleo resina de copaíba no controle de perda de massa em maracujazeiro.

Existem poucos relatos na literatura sobre pesquisas realizadas para o controle de micro-organismos fitopatogênicos com óleo de melaleuca e, as poucas pesquisas disponíveis se aplicam ao controle de doenças humanas e de outros animais (Martins et al., 2010). Hammer et al. (2004), relataram que o óleo de Melaleuca alternifolia apresenta atividade fungiostática e fungicida em dermatófitos e fungos filamentosos. Martins et al. (2010), verificaram que o óleo de Melaleuca arternifolia em concentrações a partir de $0,2 \%$ incorporado ao meio de cultura, reduziu o crescimento micelial dos fungos Macrophomina phaseolina, Sclerotinia sclerotiorum e Alternaria alternata. Barbosa et al. (2015) observaram atividade fungicida do óleo de melaleuca sobre Colletotrichum musae nas concentrações de 50, 75, 100 e 125 


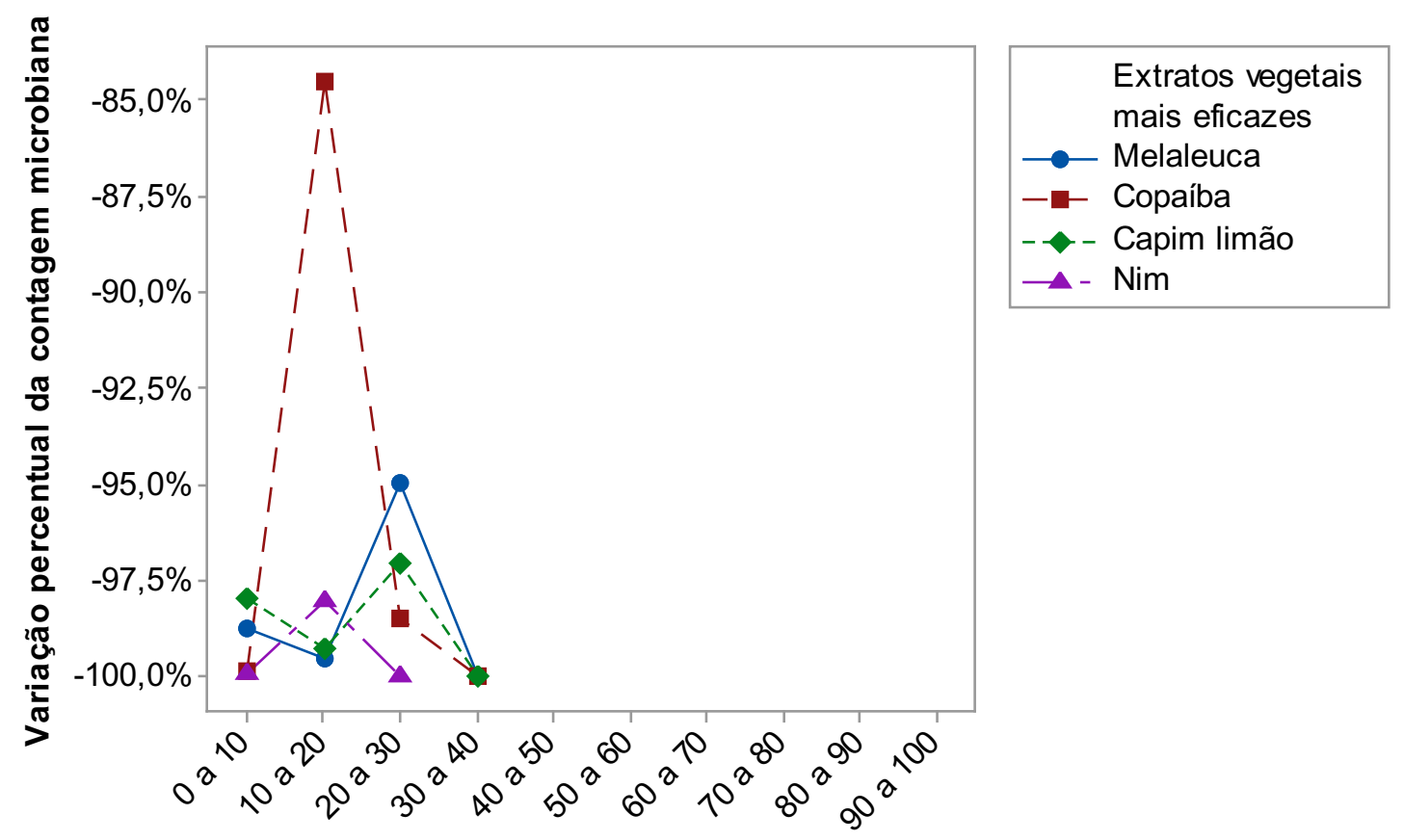

\section{Variação do tempo}

FIGURA 1. Comportamento da variação percentual da contagem microbiana em relação aos óleos essenciais e vegetais mais eficazes.

$\mu \mathrm{l} / \mathrm{L}$, enquanto que Marinelli et al. (2012) verificaram inibição total do crescimento de Colletotrichum gloeosporioides na concentração de 0,46\%. Estes resultados corroboram com os obtidos na presente pesquisa, na qual o óleo de melaleuca apresentou atividade antifúngica na concentração de $0,8 \%$, sendo necessários 40 minutos de exposição para eliminar a carga microbiana (Tabela 2, Figura 1). Os principais componentes do óleo de melaleuca são o terpinen-4-ol que apresenta atividade antimicrobiana e o 1,8-cineol, que possui propriedades irritantes à pele (Castelo et al., 2013). Considerando que o óleo utilizado nesta pesquisa continha terpinen-4-ol como componente principal (42\%), explicaria a eficácia apresentada no controle de C. gloeosporioides.

Para Colletotrichum gloeosporioides, resultados semelhantes aos da presente pesquisa, foram obtidos por Carnelossi et al. (2009) e Silva et al. (2009), utilizando $10 \mu \mathrm{L}$ e $100 \mu \mathrm{L}$, respectivamente, do óleo essencial de capimlimão (Cymbopogon citratus,), que constataram a inibição total do desenvolvimento do patógeno $C$. gloeosporioides. Guimarães et al. (2011), observaram uma alta fungitoxicidade do óleo essencial de capim-limão $(75,83 \mu \mathrm{g} / \mathrm{mL})$ e do citral $(58,24 \mu \mathrm{g} /$ $\mathrm{mL}$ ), o seu componente principal, sobre os fungos fitopatogênicos Alternaria alternata, Colletotrichum gloeosporioides, Fusarium oxysporum cubense e Bipolaris sp. Rozwalka et al. (2008), observaram atividade antifúngica sobre o desenvolvimento micelial de C. gloeosporioides utilizando $10 \mu \mathrm{L}$ do óleo essencial de capim-limão.

No presente trabalho o óleo essencial de Cymbopogon winterianus (citronela) apresentou atividade antifúngica sobre Colletotrichum gloeosporioides. Isso se deve a ação fungicida, repelente e bactericida da planta, pelo seu alto teor de geraniol e citronelal (Castro et al., 2007). Os resultados evidenciados neste estudo demonstram que o óleo essencial de manjericão apresentou redução efetiva da contagem microbiana (-97,0, Tabela 2) sobre o fungo Colletotrichum gloeosporioides, no entanto a concentração fungicida mínima foi de $100 \%$, o qual inviabilizaria a sua utilização no controle in vivo deste fitopatógeno, devido à necessidade de grandes volumes a serem empregados, o que implicaria em um elevado custo.

Schwan-Estrada et al. (2000), relataram em seus estudos in vitro que o extrato bruto e o óleo essencial de manjerona apresentaram inibição de crescimento micelial e esporulação de diversos fungos fitopatogênicos devido ao seu potencial antifúngico. Avaliando a ação in vitro do extrato de casca de canela sobre o crescimento micelial de Cladosporium cladosporioides e Colletotrichum lindemunthianum, Venturoso et al. (2011), descreveram a eficácia dos extratos de bulbos de alho, casca de canela e botão floral do cravo-da-índia e suas atividades antifúngicas em testes in vitro, realizados sobre Cercospora kikuchii, 


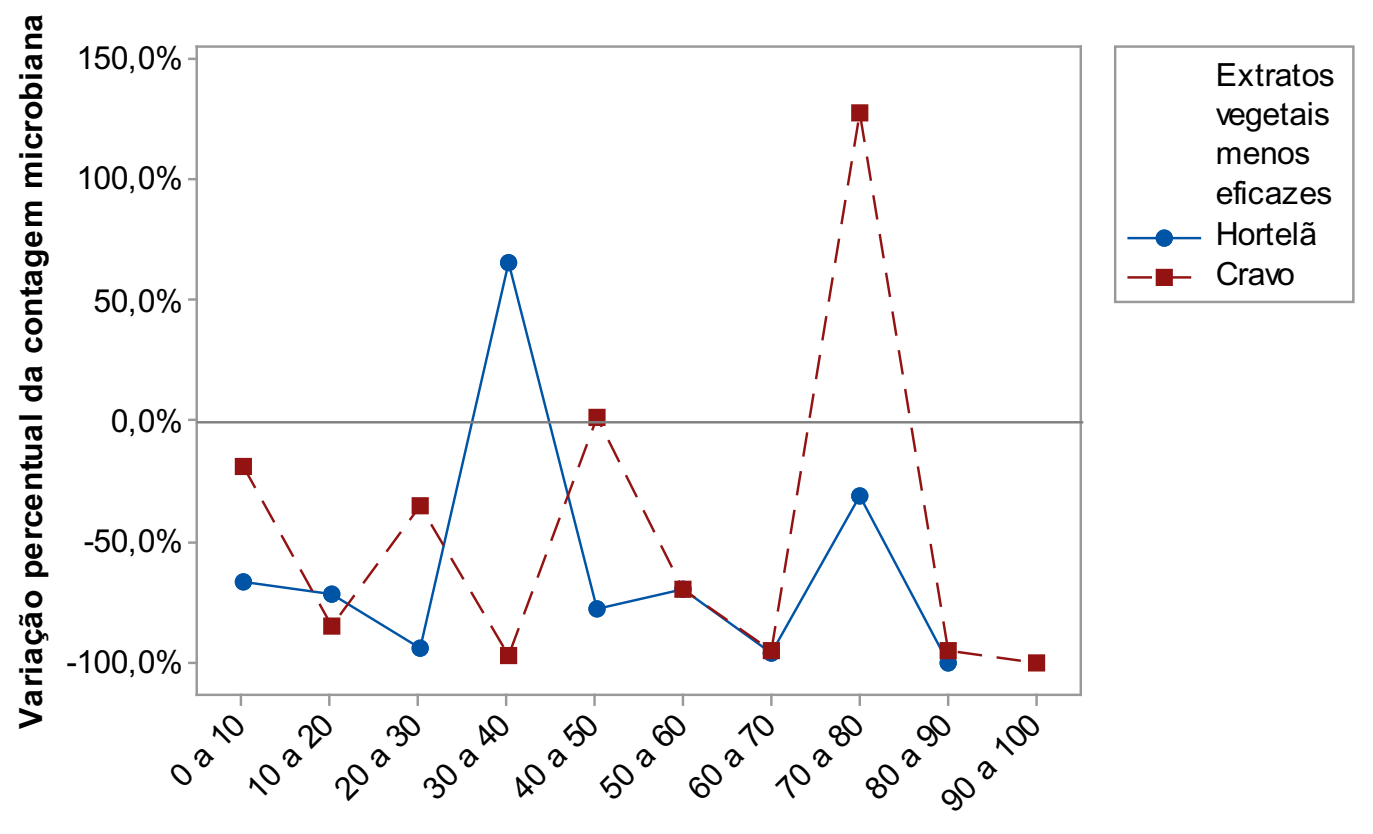

Variação do tempo

FIGURA 2. Comportamento da variação percentual da contagem microbiana em relação aos óleos essenciais e vegetais menos eficazes.

Fusarium solani, Colletotrichum sp. e Phomopsis sp. Barrera-Necha et .al. (2008), utilizando óleo essencial de Eucalyptus globulus, nas concentrações de 100, 150, 200, 250 e 300 mg/ $\mathrm{mL}$, verificaram que após dez dias de incubação não houve inibição na germinação de conídios de Colletotrichum gloeosporioides, e atribuíram a falta de atividade antifúngica à volatilidade dos princípios ativos do óleo. Na presente pesquisa foi verificada atividade antifúngica do óleo de E. globulus com CIM de $1,70 \%$, CFM 3,20\% e reduções da contagem microbiana de $-92 \%$ (Tabelas 1 e 2 ).

Estudos utilizando extratos de gengibre (Zingiber officinale) evidenciaram efeito inibitório sobre o crescimento micelial de Colletotrichum gloeosporioides, indicando o potencial desses extratos no controle da antracnose em frutos de goiabeira (Rozwalka et al., 2008). Asgar et et al.(2016), avaliaram a eficácia do óleo de gengibre $(2,0 \%)$ e extrato $(1,5 \%)$ combinado com a goma arábica(10,0\%) no controle da antracnose e na qualidade de frutos de mamão durante o armazenamento refrigerado. Os autores observaram que o óleo de gengibre combinado com a goma arábica inibiu a germinação dos conídios de C. gloeosporioides (93\%), e afirmam que estes resultados demonstraram a eficácia deste biofungicida para o controle da antracnose na póscolheita do mamão. Marinelli et al. (2012), avaliaram a atividade antifúngica in vitro do óleo de gengibre e verificaram $100 \%$ de inibição do crescimento micelial de C. gloeosporioides quando utilizaram o óleo em uma concentração de 0,05\%. Segundo estes autores para considerar a possibilidade de uso de um óleo como biofuncigida a concentração do mesmo deve ser baixa. De acordo com os resultados obtidos na presente pesquisa, CIM e CFM 50\%, (Tabela 1), inviabilizariam o seu emprego no controle da antracnose.

Os óleos essenciais de hortelã $(-71,2 \%)$ e cravo da índia $(-77,8 \%)$ foram os que apresentaram menor variação percentual, pressupondo que o micro-organismo resistiu por mais tempo à ação dos compostos bioativos componentes desses óleos (Tabela 2). Tal resultado foi comprovado pelo tempo que os mesmos necessitaram para anular a carga microbiana, sendo de 90 minutos para o óleo de hortelã e de 100 minutos para o cravo (Figura 2).

Resultados semelhantes foram observados por Santana et al. (2010), que relataram que utilizando diferentes concentrações do extrato de Syzygium aromaticum (cravo da índia), observaram inibição de apenas $15,1 \%$ do crescimento micelial de C. gloeosporiodes. Pesquisas obtendo resultados diferentes foram relatados por Venturoso et al. (2011), que ao utilizarem o extrato de cravo-daíndia (20\%), e Barbosa et al. (2015) ao usar o óleo essencial (50 $\mu \mathrm{L} / \mathrm{L})$, não observaram crescimento do fungo $C$. gloeosporioides. Ranashinge et al. (2002), constataram que o óleo de cravo apresentou ação antifúngica contra os fungos Lasiodiplodia theobromae, Colletotrichium musae e Fusarium proliferatum, isolados de banana. O óleo de Mentha piperita apresentou atividade antifúngica moderada 
sobre Colletotrichum gloeosporioidesem, em estudo realizado por Barrera-Necha et al. (2008).

Pelos resultados obtidos observou-se que é possível utilizar óleos essenciais para o controle de Colletotrichum gloeosporioides sendo que o efeito antifúngico dos óleos essenciais estudados, sobre este fungo, depende da planta e da concentração empregada. Todos os óleos essências e vegetais apresentaram atividade antifúngica sobre C. gloeosporioides, no entanto para o óleo de Melaleuca alternifolia a concentração inibitória mínima (CIM) e a concentração fungicida mínima (CFM) de 0,8\%, constata a sua ação fungicida. O óleo de Azadirachta indica apresentou maior redução da carga microbiana em função do tempo de exposição, sendo necessários 30 minutos para anulação da contagem microbiana de Colletotrichum gloeosporioides.

\section{REFERÊNCIAS}

ASGAR, A et al. Efficacy of ginger oil and extract combined with gum arabic on anthracnose and quality of papaya fruit during cold storage. Journal of Food Science and Technology, v.3, n.1, p. 1-10, 2016.

BARBOSA, MS et al. Atividade biológica in vitro de própolis e óleos essenciais sobre o fungo Colletotrichum musae isolado de bananeira (Musa spp.). Revista Brasileira de Plantas Medicinais, v.17, n.2, p.254-261, 2015.

BARRERA-NECHA, LL et al. Efficacy of essential oils on the conidial germination, growth of Colletotrichum gloeosporioides (Penz.) penz. and sacc and control of postharvest diseases in papaya (Carica papaya L.). Plant Pathology Journal, v. 7,p. 174-178, 2008.

BHUYAN, PD et al. In-Vitro Efficacy of certain essential oils and plant extracts against three major pathogens of Jatropha curcas L. American Journal of Plant Sciences, v. 6, p. 362-365, 2015.

CARNELOSSI, PR et al. Óleos essenciais no controle póscolheita de Colletotrichum gloeosporioides em mamão. Revista Brasileira de Plantas Medicinais, v. 11, n. 4 , p. 399-406, abr. 2009

CASTELO, AVM et al. Rendimento e composição química do óleo essencial de Melaleuca alternifolia Chell, na região do Distrito Federal. Revista Brasileira de Ciências Agrárias, v.8, n.1, p.143-147, 2013.

CASTRO, HG et al. Crescimento, teor e composição do óleo essencial de Cymbopogon nardus (L.). Revista Brasileira de Plantas Medicinais, v. 9, n. 4, p. 55-61, 2007.

CHIEJINA, NV; UKEH, JA. Antimicrobial properties and phytochemical analysis of methanolic extracts of Aframomum melegueta and Zingiber officinale on fungal diseases of tomato fruit. Journal of Natural Sciences Research, v. 2, p. 10-15, 2012.

CLSI - CLINICAL LABORATORY STANDARD INSTITUTE, Document M38-A2. Reference method for broth dilution antifungal susceptibility testing of filamentous fungi,
Clinical Laboratory Standard Institute (CLSI), Wayne, Pa, USA, 2nd edition, 2008, 50p.

FAVRE, B et al. Comparison of in vitro activities of antifungal drugs against a panel of 20 dermatophytes by using a microdilution assay. Journal Clinical Microbiology; v. 17. p.41-48, 2003

GUIMARÃES, LGL et al. Atividades antioxidante e fungitóxica do óleo essencial de capim-limão e do citral. Revista Ciência Agronômica, v. 42, n. 2, p. 464-472, 2011.

HAMMER, KA et al. Antifungal effects of Melaleuca alternifolia (tea tree) oil and its components on Candida albicans, Candida glabrata and Saccharomyces cerevisiae. Journal of Antimicrobial Chemotherapy, n. 53, p. 1081-1085, 2004.

LEE, Y et al. Antifungal activity of Myrtaceae essential oils and their components against three phytopathogenic fungi. Flavour Fragrance Journal, v. 23, p. 23-28, 2008.

LIMA FILHO, RM et al. Caracterização enzimática e patogenicidade cruzada de Colletotrichum spp. associados a doenças de pós-colheita. Fitopatologia Brasileira, v.28, p: 620-625. 2003.

MARINELLI, E et al. Activity of Some Essential Oils against Pathogenic Seed Borne Fungi on Legumes. Asian Journal of Plant Pathology, v. 6, p. 66-74, 2012.

MARTINS, JAS et al. Avaliação do efeito do óleo de Melaleuca alternifolia sobre o crescimento micelial in vitro de fungos fitopatogênicos. Bioscience Journal, v. 27, n. 1, p. 49-51, 2010.

MARTINEZ, SS. O Nim - Azadirachta indica: natureza, usos múltiplos, produção. 1.ed, Londrina: Instituto Agronômico do Paraná, 2002. 142p.

OGBEBOR, NO et al. Inhibition of Colletotrichum gloeosporioides (Penz) Sacc. causal organism of rubber (Hevea brasiliensis Muell. Arg.) leaf spot using plant extracts. African Journal of Biotechnology, v. 6, n. 3, p. 213-218, 2007.

OLIVEIRA, FC; LOBATO, AKS; GUEDES, EMS; FREITAS, MQ; MAIA, PR; SANTOS, DGC. Avaliação do crescimento micelial de Cylindrocladium sp. submetido a meios de cultura preparado com extrato aquoso de Icthyothere cunabi Mart. In: III CONGRESSO BRASILEIRO DE DEFENSIVOS AGRÍCOLAS NATURAIS, 15, Belém, 2006, Resumos. Embrapa: Belém, 2006, p. 158.

PERUCH, LAM; SCHROEDER,AL; COLARICCIO,A; CHAGAS,CM.; GUIMARÃES, L. Doenças do maracujazeiro amarelo. Florianópolis: Epagri, Boletim técnico, 145. 2009. 99 p.

PIERI, FA et al. Óleo de copaíba (Copaifera sp.): histórico, extração, aplicações industriais e propriedades medicinais. Revista Brasileira de Plantas Medicinais, v.11, n.4, p.465-472, 2009.

ROZWALKA, LC et al.Extratos, decoctos e óleos essenciais de plantas medicinais e aromáticas na inibição de Glomerella cingulata e Colletotrichum gloeosporioides de frutos de goiaba. Ciência Rural, v. 38, n. 2, p. 301-307, 2008.

SANTANA, KFA; DEZORDI, C; COELHO NETO, RA; ASSIS, LAG. Efeito fungitóxico de extratos vegetais sobre Colletotrichum gloesosporioides. In: CONGRESSO BRASILEIRO DE FITOPATOLOGIA, 43. Cuiabá. Resumos... Cuiabá: SBF, 2010. p. 402.

SARMENTO-BRUM, RBC et al. Effect of plant oils in 
inhibiting the mycelial growth of pathogenic fungi. Journal of Biotechnology and Biodiversity v. 5, n.1, p. 63-70, 2014.

SCHWAN-ESTRADA, KRF et al. Uso de plantas medicinais no controle de doenças de plantas. Uso de extratos vegetais no controle de fungos fitopatogênicos. Revista Floresta, v.30, n.1, p.129-37, 2000.

SFORCIN, JM et al. Seasonal effect on Brazilian própolis antibacterial activity. Journal Ethnopharmics, v.73, p. 243-249, 2000.

SILVA, KS et al. Patogenicidade causada pelo fungo Colletotrichum gloesporioides (Penz) em diferentes espécies frutíferas. Revista Brasileira de Fruticultura, v. 28, n. 1, p. 131-133, 2006.

SILVA, AC et al. Efeito in vitro de compostos de plantas sobre o fungo Colletotrichum gloeosporioides Penz. isolado do maracujazeiro. Ciência e Agrotecnologia, v. 33, Edição Especial, p. 1853 -1860, 2009.

SILVA, MB et al. Uso de princípios bioativos de plantas no controle de fitopatógenos e pragas. Informe Agropecuário, v. 31, n. 255, p. 70-77, 2010.

SILVA, RA et al. Inibição do crescimento micelial e germinação de Colletotrichum gloeosporioides na seringueira pelo óleo de neem. Nucleus, v. 8, n. 1 , p.295-304, 2011.

SILVA, JL. et al. Antifungal activity using medicinal plant extracts against pathogens of coffee tree. Revista brasileira de plantas medicinais, v.16, n. 3, p. 539544, 2014.

SYLVESTER, PW. Optimization of the tetrazolium dye
(MTT) colorimetric assay for cellular growth and viability. Methods in Molecular Biology, v.716, p.157-168, 2011.

SOLINO, AJS et al. Severidade da antracnose e qualidade dos frutos de maracujá-amarelo tratados com produtos naturais em pós-colheita. Revista Brasileira de Fruticultura, v.34, p.57-66, 2012.

SOUSA, RMS et al. Efeito de óleos essenciais como alternativa no controle de Colletotrichum gloeosporioides, em pimenta. Summa Phytopathologica, v. 38, n. 1, p. 42-47, 2012.

SOYLU, EM et al. In vitro and in vivo antifungal activities of the essential oils of various plants against tomato grey mould disease agent Botrytis cinerea. International Journal of Food Microbiology, v. 143, n. 3, p. 183189, 2010.

TAVARES, GM. Controle químico e hidrotérmico da antracnose em frutos de mamoeiro (Carica papaya L.) na pós-colheita. 2004. 55p. Dissertação (Mestrado em Fitopatologia) - Departamento de Fitopatologia, Universidade Federal de Lavras, Lavras-MG.

VENTUROSO, LR et al. Influência de diferentes metodologias de esterilização sobre a atividade antifúngica de extratos aquosos de plantas medicinaisUniversidade Federal da Grande Dourados, Faculdade de Ciências Agrárias-Brasil. Revista Brasileira de Plantas Medicinais, v. 12, n. 4, p. 499-505, 2010.

VENTUROSO, LR et al. Inibição do crescimento in vitro de fitopatógenos sob diferentes concentrações de extratos de plantas medicinais. Arquivos do Instituto Biológico, v.78, n.1, p.89-95, 2011. 